\title{
Image-guided high-dose-rate brachytherapy of head and neck - a case series study
}

\author{
Paweł Cisek, MD',2, Dariusz Kieszko, PhD', Anna Brzozowska, PhD², Izabela Kordzińska-Cisek, MD³, \\ Prof. Maria Mazurkiewicz, MD, PhD² \\ 'Department of Brachytherapy, Lublin Region Cancer Center, ${ }^{2}$ Department of Oncology, Medical University of Lublin, ${ }^{3}$ Department of Clinical \\ Oncology, Lublin Region Cancer Center, Lublin, Poland
}

\begin{abstract}
Purpose: The aim of the study was the evaluation of image guided transdermal application of interstitial brachytherapy in patients undergoing repeated irradiation for relapsed local tumor of the head and neck area.

Material and methods: The article describes transdermal application of interstitial high-dose-rate (HDR) brachytherapy in 4 patients treated due to relapsed local tumor in soft palate, submandibular area, laryngopharynx, as well as pterygoid muscles and maxillary sinus. The application was conducted under continuous computed tomography (CT)-image guidance (CT fluoroscopy). Patients qualified for this type of treatment had neoplastic lesions located deep under the skin surface. Because of their location, access to the lesions was limited, and the risk of damaging the adjacent tissues such as vessels and nerves was high. The following parameters have been evaluated: clinical response using RECIST 1.1, incidence of perisurgical complications using CTCAE 4.0 and the frequency of occurrence of radiotherapy related early morbidity using RTOG.

Results: Various radiation schemes were used, from 3 to 5 fractions of 3.5-5 Gy. The median total dose $\left(D_{90}\right)$ was 20.6 Gy. Biologic effective dose (BED) and equivalent $2 \mathrm{~Gy}\left(\mathrm{DEQ}_{2}\right)$ median doses were $30.4 \mathrm{~Gy}$ and $25.3 \mathrm{~Gy}$, respectively. In the follow-up period of 3-7 months (the median value of 3.5 months), 2 patients had partial regression of the disease and in 2 others the neoplastic process was stabilized. None of the patients had serious complications of treatment (of $3^{\text {rd }}$ degree or higher).

Conclusions: Computed tomography-image guided brachytherapy proved to be a safe method of treatment in patients with local relapse in sites, in which traditional visually controlled application was impossible due to risk of complications. Despite short observation period and small study group, it seems justified to conduct prospective studies for the evaluation of efficacy and safety of CT-image guided brachytherapy.
\end{abstract}

Key words: brachytherapy, CT-image guided, head and neck.

\section{Purpose}

Despite significant progress in head and neck cancer treatment, relapse still occurs in $17-30 \%$ patients with this type of neoplasm [1]. The basic method of local treatment of relapse in these patients is surgery or repeated radiotherapy. Salvage surgery, due to the risk of complications and the necessity of conducting extensive, often maiming, surgery, is only possible in $20 \%$ cases [2]. The possibility of repeated irradiation is also limited due to high risk of radiotherapy related morbidity. In case of brachytherapy, the relapsed lesion location creates a limitation, which in many cases prevents correct placement of brachytherapy applicators in tumor [3]. Traditionally, brachytherapy is reserved for application in surface lesions where the risk of mechanical damages and surgery related complications is small. In case of deep lesions, due to high risk of complications in course of application, the use of brachytherapy is marginal. This article presents a technique of computed tomography (CT) image-guided transdermal application of interstitial brachytherapy possible in patients with relapsed tumor in hardly accessible areas. The utilization of CT for imaging of the application site allows to decrease the risk of damaging important anatomical structures and accurate distribution of applicators within the tumor.

\section{Material and methods \\ Treatment qualification}

Patients with neoplastic lesions located deep under the skin surface in hardly accessible areas were qualified for treatment using image-guided brachytherapy. The lesions were located in close vicinity to critical organs such as spinal cord, trachea, eyeball, lens, or directly adjacent to large vessels or structures, whose mechanical damage
Address for correspondence: Paweł Cisek, MD, Department of Brachytherapy, Lublin Region Cancer Center, 7 Jaczewskiego St., 20-090 Lublin, Poland, phone: +48 512190 145, « e-mail: pcisek@interia.eu
Received: 08.05 .2016

Accepted: 01.09 .2016

Published: 30.12 .2016 
could lead to hemorrhage, paralysis, or organ dysfunction. This distinguished our image-guided brachytherapy of visually controlled procedure applied on the basis of tumor extent, determined in physical examination or formerly conducted imaging examinations.

The study involves analysis of data concerning 4 patients with local relapse of head and neck cancer treated in the Department of Brachytherapy, Lublin Region Cancer Center in 2013-2015. All patients had undergone radical treatment with external beam radiotherapy. In all patients, an isolated inoperable local relapse occurred, for which brachytherapy was applied assumed as palliative treatment. The indications for application of image guided brachytherapy were above all close vicinity of large blood vessels (all patients), the organ of vision (Patient 4), the extent of the neoplastic process (Patient 2), and small relapsed tumor size requiring precise application (Patient 1). The patients' characteristics is presented in Table 1.

\section{Application technique}

The procedure was conducted under general (Patients 2, 3 and 4) or local anesthesia (Patient 1). Under local anesthesia, we have used 1\% Lignocaine after former premedication with Midazolam and Fentanyl. Steel or titanium needle applicators, as well as elastic interstitial applicators were used in brachytherapy. In sites, where it was impossible to drive the applicators through the lesion, needle applicators were used. The applicators had an advantage of being well visible in tomographic examination. A disadvantage was the necessity of conducting the treatment in several stages, which was associated with the need for performing several application procedures, as well as several steps of treatment planning. Elastic applicators were used in cases when it was possible to form an applicator outlet on the other side of the tumor. Due to poor visibility of the placed applicators, it was necessary to apply markers just after the ap-

Table 1. Clinical characteristics of patients

\begin{tabular}{|c|c|c|c|c|}
\hline & Patient 1 & Patient 2 & Patient 3 & Patient 4 \\
\hline Gender & Male & Male & Male & Male \\
\hline Age & 72 & 68 & 63 & 59 \\
\hline Diagnosis & Oropharyngeal cancer & Lip cancer & Larynx cancer & Maxillary cancer \\
\hline TNM & T4N1MO & T3N3MO & T2NOMO & T3NOMO \\
\hline Histopathology & $\begin{array}{l}\text { Squamous cell carcinoma } \\
\text { Gl and Gll }\end{array}$ & $\begin{array}{l}\text { Squamous cell carcinoma } \\
\text { Gl }\end{array}$ & $\begin{array}{c}\text { Squamous cell carcinoma } \\
\text { Gll }\end{array}$ & $\begin{array}{c}\text { Squamous cell carcinoma } \\
\text { Gll }\end{array}$ \\
\hline Surgical treatment & $\begin{array}{l}\text { Resection of the retro- } \\
\text { molar trigone tumor, } \\
\text { base of the tongue and } \\
\text { floor of the mouth on the } \\
\text { left side. } \\
\text { Radical neck dissection } \\
\text { on the left side }\end{array}$ & - & $\begin{array}{l}\text { Partial laryngectomy, } \\
\text { total laryngectomy }\end{array}$ & $\begin{array}{l}\text { Resection of the maxillary } \\
\text { sinus on the right side }\end{array}$ \\
\hline Radiotherapy & IMRT - 66 Gy & $2 \times 20 G y$ & IMRT - 66 Gy & IMRT - 66 Gy \\
\hline Chemotherapy & - & Cisplatin & Cisplatin and Paclitaxel & Cisplatin \\
\hline Recurrence location & $\begin{array}{l}\text { Hard palate on the right } \\
\text { side }\end{array}$ & Nodes groups: I and IIA & $\begin{array}{l}\text { Peristomal area, pharynx- } \\
\text { esophageal connection }\end{array}$ & $\begin{array}{c}\text { Maxillary sinus area, } \\
\text { pterygomandibularis } \\
\text { space }\end{array}$ \\
\hline $\begin{array}{l}\text { Number } \\
\text { of applicators }\end{array}$ & 4 & 9 & 3 & $4-5$ \\
\hline Type of applicators & Needless & Elastic & Elastic & Needless \\
\hline EBRT schema & $\begin{array}{c}\text { Df } 5 \\
\text { Dc } 20\end{array}$ & $\begin{array}{l}\text { Df } 3.5 \\
\text { Dc } 17\end{array}$ & $\begin{array}{c}\text { Df } 4 \\
\text { Dc } 20\end{array}$ & $\begin{array}{c}\text { Df } 5 \\
\text { Dc } 15\end{array}$ \\
\hline Follow-up & 3 months & 7 months & 4 months & 3 months \\
\hline $\begin{array}{l}\text { Treatment } \\
\text { efficiency RECIST }\end{array}$ & PR & PR & SD & SD \\
\hline Toxicity CTCAE & - & Skin infection II grade & - & - \\
\hline $\begin{array}{l}\text { Radiotherapy } \\
\text { related morbidity } \\
\text { RTOG }\end{array}$ & - & $\begin{array}{l}\text { Skin radiotherapy } \\
\text { induced morbidity I grade }\end{array}$ & $\begin{array}{l}\text { Skin radiotherapy } \\
\text { induced morbidity I grade }\end{array}$ & $\begin{array}{l}\text { Skin radiotherapy } \\
\text { induced morbidity I grade }\end{array}$ \\
\hline
\end{tabular}




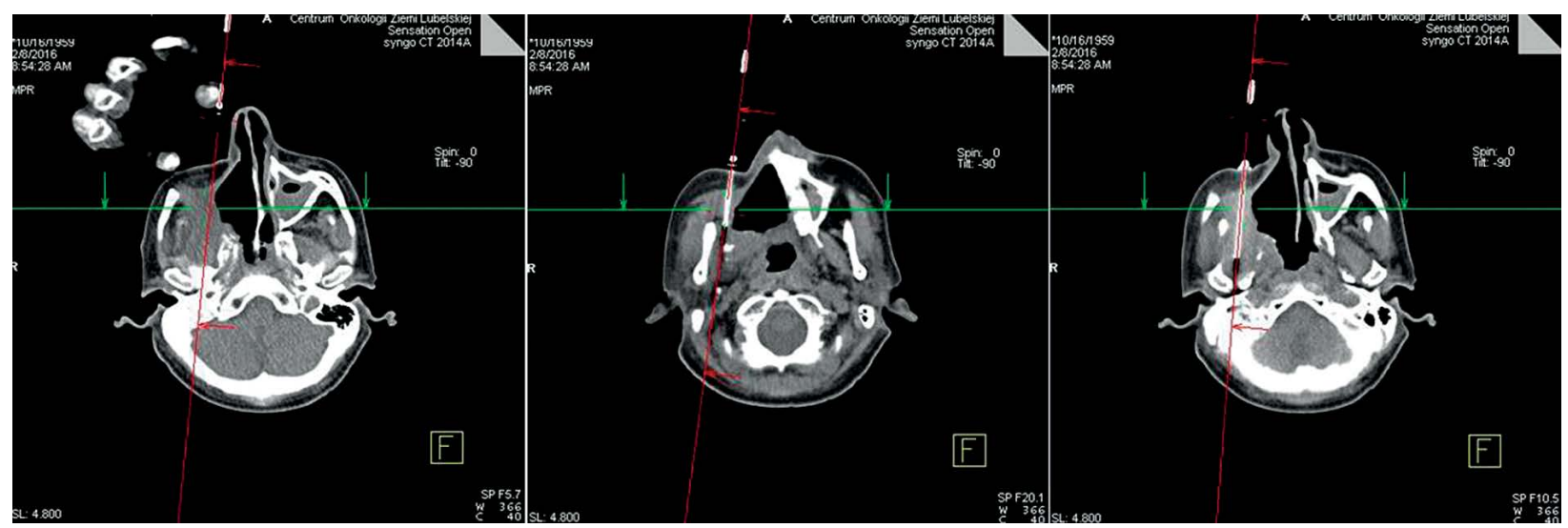

Fig. 1. Computed tomography-guided applicators, next steps (Patient 4)

plication. After applicators were in place, they remained in the lesion throughout the treatment process. The application was conducted under guidance of CT device located in the operating room and moving on rails. Both, the CT device and the operating table movement were controlled using a console located in the operating room. SOMATOM Sensation OPEN CT device (Siemens AG, Munich, Germany) was used including optional fluoroscopy accessory from Siemens.

Before the commencement of the treatment, CT examination was conducted with or without contrast agent, and then, the image was fused with the previously performed CT or magnetic resonance imaging (MRI) examination. The extent of the tumor was determined on the basis of the conducted examinations and projected on patient's skin using laser beams. Then, under continuous CT guidance, applicator needle or elastic applicator lead was percutaneously (transdermally) inserted into the tumor in a way facilitating irradiation of the whole tumor area, and simultaneously controlling the position of the needle against the adjacent structures (Figure 1). If it was possible, the applicators were inserted in such a way that their layout in the lesion was possibly most parallel, and their distance from one another as well as from the edge of the tumor was not greater than $2 \mathrm{~cm}$. Technical difficulties were encountered in cases requiring the insertion of an applicator under different angles

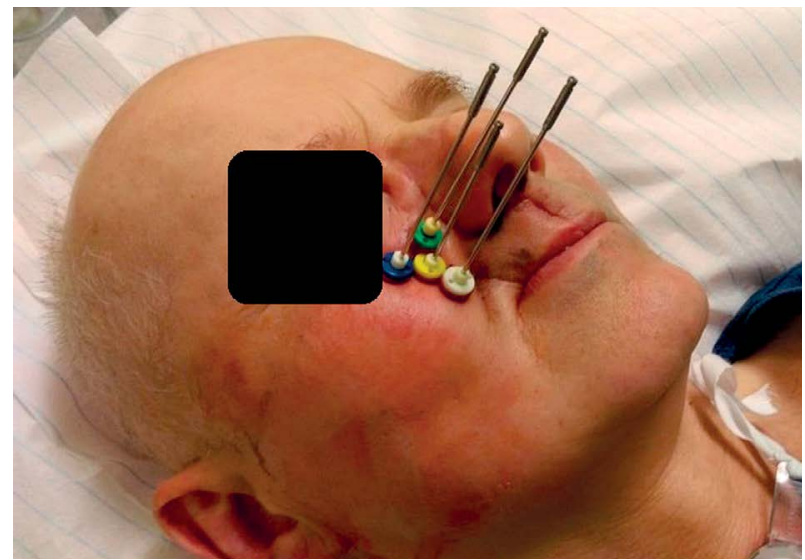

Fig. 2. Patient 4 with applicators towards the tomographic image plane. It was associated with the necessity of constant control of needle position at the time of insertion on several tomographic scans simultaneously. Due to little respiratory movement of anatomic structures in head and neck region, CT guided insertion of the needle was precise and relatively safe, despite close vicinity of many important organs. Only the region directly under the needle was not sufficiently visible due to artifacts related to the material, of which the needle was made. Needle applicators were located in the lesion only during each fraction of treatment but elastic applicators, used for their stabilization, remained in the tumor from the beginning of the first to the end of the last fraction (Figure 2).

On the completion of a single treatment session, CT scan was performed to plan further treatment, and then, after drawing the clinical target volume (CTV) and organs at risk (OAR), time and place of ionizing radiation source stopping points were planned. BrachyVision v.10 treatment planning system from Varian (Varian Medical Systems, Inc., Palo Alto, CA, USA) was used (Figure 3). Dosimetry parameters were reported according to the guidelines outlined in ICRU Report 58 [4]. The condition for treatment plan acceptance was encompassing the total CTV with a dose constituting $90 \%$ of the planned dose $\left(D_{90}\right)$. Additionally, the minimum significant dose for local control of the tumor was reported $\left(D_{100}\right)$. These doses and total doses were converted according to linear quadratic model of biologic effective dose (BED), using the following formula BED $=$ nd $(1+d /(\alpha / \beta))$, where $d$ - fractional dose, $n$ - number of fractions, $\alpha / \beta$ - alpha/ beta ratio, in case of squamous cell carcinoma of head and neck it is 10. In order to compare them with conventional fractioning of $2 \mathrm{~Gy}$, the doses were converted to dose equivalent $2 \mathrm{~Gy}\left(\mathrm{DEQ}_{2}\right)$ using the following formula: $\mathrm{DEQ}_{2}=\mathrm{BED} /(1+2 /(\alpha / \beta))$. In order to facilitate the evaluation of correlation between the dose and possible future damages, the volume receiving $100 \%$ of the prescribed dose was reported, as well as high dose areas receiving $150 \%$ of the prescribed dose $\left(\mathrm{V}_{150}\right)$ and $200 \%$ of the prescribed dose $\left(\mathrm{V}_{200}\right)$. Biologic effective dose and $\mathrm{DEQ}_{2}$ were calculated for each fraction.

Due to various locations, doses received by critical organs were also reported. Depending on the type of the 


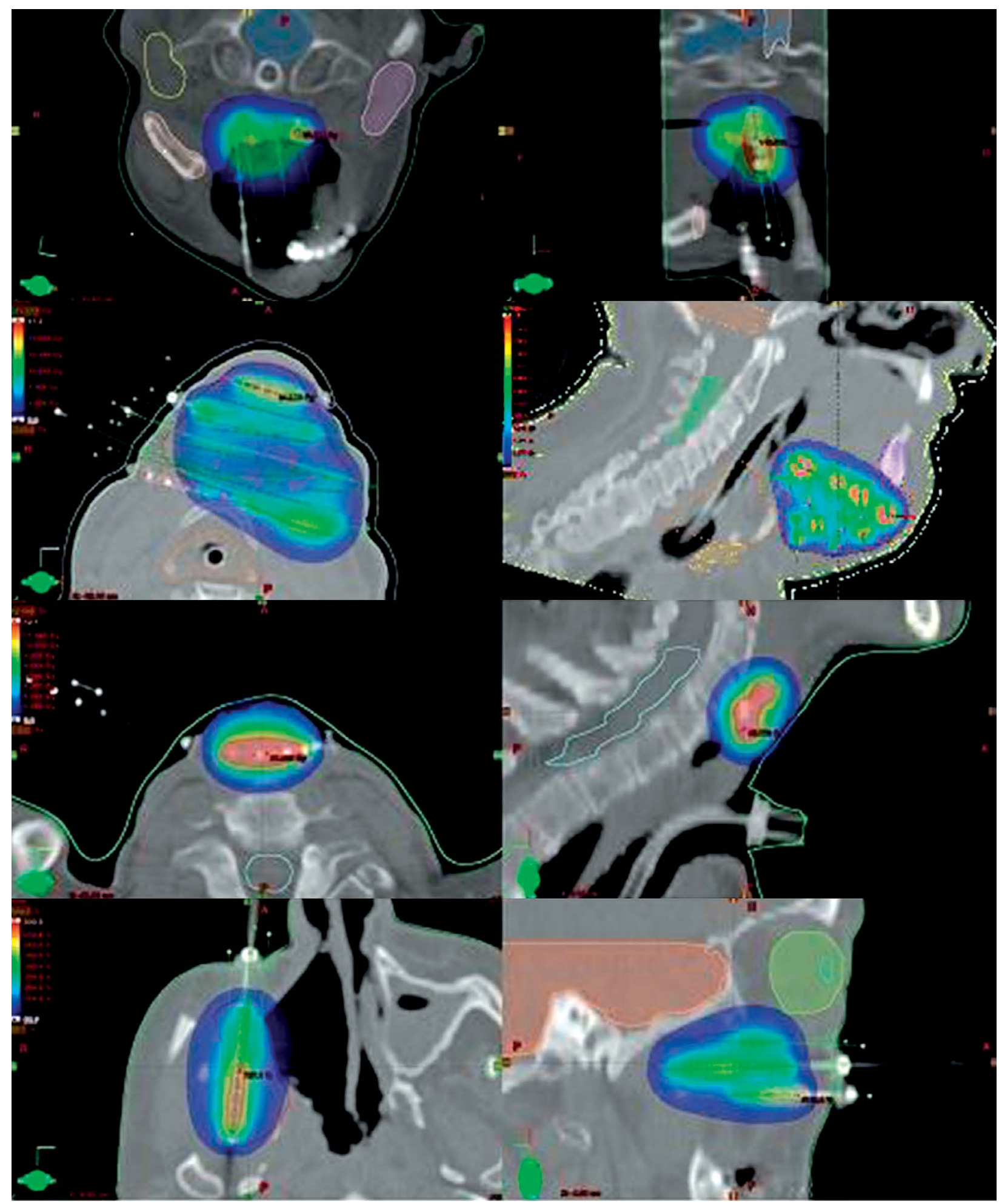

Fig. 3. The image-guided high-dose-rate (IG-HDR) plan for patients. The color code for the isodose color wash is as follows: red $200 \%$, orange $150 \%$, yellow $110 \%$, green $100 \%$, blue $90 \%$ (transverse view - left, sagittal view - right) 
organ, either maximum dose $\left(D_{\max }\right)$ or dose per $1 \mathrm{~cm}^{3}$ of the organ located in the maximum dose area $\left(D_{1 \mathrm{~cm}^{3}}\right)$ were reported. The doses were converted to $\mathrm{BED}$ and to $\mathrm{DEQ}_{2}$ according to the linear quadratic model, adopting $\alpha / \beta$ ratio value of 3 for future radiation induced complications.

The treatment was conducted using 24 channel Gammamed Plus device from Varian (Varian Medical Systems, Inc., Palo Alto, CA, USA). After completion of irradiation session, applicators were removed from lesions. If it was necessary, the removal was conducted after premedication with opioid analgesics. Because of the risk of hemorrhage, the surgical procedure was conducted in an operating room equipped with GE OEC 9900 Elite System (GE Health Care, Milwaukee, WI, USA), and offering the possibility of interventional embolization of a damaged vessel by a surgical radiology specialist. After applicators removal, CT scan with contrast was performed in order to rule out potential complications, especially fresh bleeding in the applicator area.

\section{Results}

Various fractioning schemes were used depending on the possibility of retaining the applicators within the lesion. In 2 patients (Patient 2 and 3 ) brachytherapy was performed using elastic applicators. Five fractions of $3 \mathrm{~Gy}$ or $4 \mathrm{~Gy}$ were used in 1 day intervals. This required a single application procedure and a single treatment planning session. The applicator insertion was performed in general anesthesia and after completion of the whole treatment process, the applicators were removed. In the other patients, needle applicators were used and the insertion and treatment planning were performed before each treatment session. Due to this fact, fractional doses were higher (5 Gy/ fraction) and the interval between sessions was longer (from 3 to 7 days). In one patient, the insertion procedure was performed in general anesthesia and in the others, in local anesthesia after premedication. The applicators were removed after each treatment session. Fractional dose median was 4 Gy (3.5-5 Gy). $\mathrm{D}_{100}$ median of a single fraction

Table 2. Doses for individual patients

\begin{tabular}{|c|c|c|c|c|c|c|c|c|c|c|}
\hline & $\mathrm{D}_{100 \%}$ & $\mathrm{D}_{90 \%}$ & $\mathrm{~V}_{100 \%}$ & $\mathrm{~V}_{150 \%}$ & $V_{200 \%}$ & $\mathrm{DHI}$ & BED $D_{100 \%}$ & BED $D_{90 \%}$ & $\mathrm{DEQ}_{2} \mathrm{D}_{100 \%}$ & $\mathrm{DEQ}_{2} \mathrm{D}_{90 \%}$ \\
\hline \multicolumn{11}{|l|}{ Patient 1} \\
\hline Fr 1 & 4.0 & 5.8 & 16.5 & 11.8 & 8.4 & 0.28 & 5.6 & 9.2 & 4.7 & 7.6 \\
\hline Fr 2 & 4.2 & 5.8 & 12.0 & 10.0 & 7.8 & 0.17 & 6.0 & 9.2 & 5.0 & 7.6 \\
\hline Fr 3 & 3.8 & 5.6 & 14.6 & 10.2 & 7.6 & 0.30 & 5.2 & 8.7 & 4.4 & 7.3 \\
\hline Fr 4 & 3.7 & 5.4 & 18.4 & 11.5 & 9.2 & 0.38 & 5.1 & 8.3 & 4.2 & 6.9 \\
\hline Amount & 15.7 & 22.6 & - & - & - & - & 21.9 & 35.4 & 18.2 & 29.5 \\
\hline \multicolumn{11}{|l|}{ Patient 2} \\
\hline $\mathrm{Fr} 1$ & 3.0 & 3.7 & 225.6 & 72.0 & 41.0 & 0.68 & 3.9 & 5.1 & 3.3 & 4.2 \\
\hline Fr 2 & 3.0 & 3.7 & 225.6 & 72.0 & 41.0 & 0.68 & 3.9 & 5.1 & 3.3 & 4.2 \\
\hline Fr 3 & 3.0 & 3.7 & 225.6 & 72.0 & 41.0 & 0.68 & 3.9 & 5.1 & 3.3 & 4.2 \\
\hline $\mathrm{Fr} 4$ & 3.0 & 3.7 & 225.6 & 72.0 & 41.0 & 0.68 & 3.9 & 5.1 & 3.3 & 4.2 \\
\hline Fr 5 & 3.0 & 3.7 & 225.6 & 72.0 & 41.0 & 0.68 & 3.9 & 5.1 & 3.3 & 4.2 \\
\hline Amount & 15.0 & 18.5 & - & - & - & - & 19.5 & 25.3 & 16.3 & 21.1 \\
\hline \multicolumn{11}{|l|}{ Patient 3} \\
\hline $\mathrm{Fr} 1$ & 3.9 & 5.2 & 14.1 & 9.7 & 6.2 & 0.31 & 5.4 & 7.9 & 4.5 & 6.6 \\
\hline $\mathrm{Fr} 2$ & 3.9 & 5.2 & 14.1 & 9.7 & 6.2 & 0.31 & 5.4 & 7.9 & 4.5 & 6.6 \\
\hline $\mathrm{Fr} 3$ & 3.9 & 5.2 & 14.1 & 9.7 & 6.2 & 0.31 & 5.4 & 7.9 & 4.5 & 6.6 \\
\hline Fr 4 & 3.9 & 5.2 & 14.1 & 9.7 & 6.2 & 0.31 & 5.4 & 7.9 & 4.5 & 6.6 \\
\hline Fr 5 & 3.9 & 5.2 & 14.1 & 9.7 & 6.2 & 0.31 & 5.4 & 7.9 & 4.5 & 6.6 \\
\hline Amount & 19.5 & 26.0 & - & 48.5 & 31.0 & - & 27.1 & 39.5 & 22.6 & 32.9 \\
\hline \multicolumn{11}{|l|}{ Patient 4} \\
\hline Fr 1 & 3.8 & 5.6 & 15.9 & 13.0 & 9.8 & 0.18 & 5.2 & 8.7 & 4.4 & 7.3 \\
\hline Fr 2 & 3.2 & 5.2 & 23.7 & 18.0 & 13.8 & 0.24 & 4.2 & 7.9 & 3.5 & 6.6 \\
\hline Fr 3 & 3.0 & 5.3 & 22.7 & 18.1 & 15.4 & 0.20 & 3.9 & 8.1 & 3.3 & 6.8 \\
\hline Amount & 10.0 & 16.1 & - & 49.1 & 39.0 & - & 13.4 & 24.7 & 11.1 & 20.6 \\
\hline
\end{tabular}

$D_{100 \%}$ - \% of prescription dose covering $100 \%$ of target volume; $D_{90 \%}-\%$ of prescription dose covering $90 \%$ of target volume; $V_{100 \%}, V_{150 \%}, V_{200 \%}-\%$ of target volume receiving prescription dose, $150 \%$ of prescription dose and $200 \%$ of prescription dose; $D H I$ - dose homogeneity index; $B E D D_{100 \%}-$ biologic effective dose in $D_{100 \%}$; $B E D D_{90 \%}$ - biologic effective dose in $D_{90 \%} ; D E Q_{2} D_{100 \%}$-dose equivalent 2 Gy in $D_{100 \%}$; $D E Q_{2} D_{90 \%}$-dose equivalent 2 Gy in $D_{90 \%}$; Fr - fractions 
Table 3. Doses in critical organs: brain, spinal cord, and eyeballs in individual patients

\begin{tabular}{|c|c|c|c|c|c|c|c|c|c|c|c|c|}
\hline & $\begin{array}{c}\text { Spinal } \\
\text { cord } \\
\max \end{array}$ & $\begin{array}{l}\text { BED } \\
\text { spinal } \\
\text { cord }\end{array}$ & $\begin{array}{c}\mathrm{DEQ}_{2} \\
\text { spinal } \\
\text { cord }\end{array}$ & $\begin{array}{l}\text { Brain } \\
1 \mathrm{~cm}^{3}\end{array}$ & $\begin{array}{l}\text { BED } \\
\text { brain }\end{array}$ & $\begin{array}{l}\mathrm{DEQ}_{2} \\
\text { brain }\end{array}$ & $\begin{array}{l}\text { Eye } \\
\text { I. max. }\end{array}$ & $\begin{array}{l}\text { BED } \\
\text { eye I. }\end{array}$ & $\begin{array}{l}\mathrm{DEQ}_{2} \\
\text { eye I. }\end{array}$ & $\begin{array}{c}\text { Eye } \\
\text { r. max. }\end{array}$ & $\begin{array}{l}\text { BED } \\
\text { eye } r \text {. }\end{array}$ & $\begin{array}{l}\mathrm{DEQ}_{2} \\
\text { eye } \mathrm{r} \text {. }\end{array}$ \\
\hline \multicolumn{13}{|l|}{ Patient 1} \\
\hline $\mathrm{Fr} 1$ & 1.4 & 2.1 & 1.2 & 1.2 & 1.7 & 1.0 & - & - & - & - & - & - \\
\hline $\operatorname{Fr} 2$ & 1.0 & 1.3 & 0.8 & 1.0 & 1.3 & 0.8 & - & - & - & - & - & - \\
\hline $\mathrm{Fr} 3$ & 1.3 & 1.9 & 1.1 & 1.6 & 2.5 & 1.5 & - & - & - & - & - & - \\
\hline $\mathrm{Fr} 4$ & 1.5 & 2.3 & 1.3 & 1.1 & 1.5 & 0.9 & - & - & - & - & - & - \\
\hline Amount & 5.2 & 7.5 & 4.5 & 4.9 & 7.0 & 4.2 & - & - & - & - & - & - \\
\hline \multicolumn{13}{|l|}{ Patient 2} \\
\hline $\mathrm{Fr} 1$ & 0.7 & 0.9 & 0.5 & 2.3 & 4.1 & 2.4 & 0.3 & 0.3 & 0.2 & 0.2 & 0.2 & 0.1 \\
\hline $\operatorname{Fr} 2$ & 0.7 & 0.9 & 0.5 & 2.3 & 4.1 & 2.4 & 0.3 & 0.3 & 0.2 & 0.2 & 0.2 & 0.1 \\
\hline Fr 3 & 0.7 & 0.9 & 0.5 & 2.3 & 4.1 & 2.4 & 0.3 & 0.3 & 0.2 & 0.2 & 0.2 & 0.1 \\
\hline Fr 4 & 0.7 & 0.9 & 0.5 & 2.3 & 4.1 & 2.4 & 0.3 & 0.3 & 0.2 & 0.2 & 0.2 & 0.1 \\
\hline Fr 5 & 0.7 & 0.9 & 0.5 & 2.3 & 4.1 & 2.4 & 0.3 & 0.3 & 0.2 & 0.2 & 0.2 & 0.1 \\
\hline Amount & 3.5 & 4.3 & 2.6 & 11.5 & 20.3 & 12.2 & 1.5 & 1.7 & 1.0 & 1.0 & 1.1 & 0.6 \\
\hline \multicolumn{13}{|l|}{ Patient 3} \\
\hline Fr 1 & 1.3 & 1.9 & 1.1 & - & - & - & - & - & - & - & - & - \\
\hline Fr 2 & 1.3 & 1.9 & 1.1 & - & - & - & - & - & - & - & - & - \\
\hline $\mathrm{Fr} 3$ & 1.3 & 1.9 & 1.1 & - & - & - & - & - & - & - & - & - \\
\hline Fr 4 & 1.3 & 1.9 & 1.1 & - & - & - & - & - & - & - & - & - \\
\hline Fr 5 & 1.3 & 1.9 & 1.1 & - & - & - & - & - & - & - & - & - \\
\hline Amont & 6.5 & 9.3 & 5.6 & - & - & - & - & - & - & - & - & - \\
\hline \multicolumn{13}{|l|}{ Patient 4} \\
\hline Fr 1 & 0.4 & 0.5 & 0.3 & 2.1 & 3.6 & 2.1 & 0.4 & 0.5 & 0.3 & 3.9 & 9.0 & 5.4 \\
\hline Fr 2 & 0.5 & 0.6 & 0.3 & 2.7 & 5.1 & 3.1 & 0.4 & 0.5 & 0.3 & 3.0 & 6.0 & 3.6 \\
\hline $\mathrm{Fr} 3$ & 0.7 & 0.9 & 0.5 & 3.0 & 6.0 & 3.6 & 0.5 & 0.6 & 0.3 & 5.4 & 15.1 & 9.1 \\
\hline Amount & 1.6 & 1.9 & 1.1 & 7.8 & 14.7 & 8.8 & 1.3 & 1.5 & 0.9 & 12.3 & 30.1 & 18.0 \\
\hline
\end{tabular}

Spinal cord max., Eye l. max., Eye r. max. - maximum dose in spinal cord and left and right eyeballs; Brain $1 \mathrm{~cm}^{3}$ - dose in $1 \mathrm{~cm}^{3}$ of brain tissue; BED spinal cord, BED eye l., BED eye r. - biologic effective dose of maximum dose in spinal cord and left and right eyeballs; BED brain - biologic effective dose of the dose in $1 \mathrm{~cm}^{3}$ of brain tissue; $D E Q_{2}$ spinal cord, $D E Q_{2}$ eye l., $D E Q_{2}$ eye r. - dose equivalent 2 Gy of maximum dose in spinal cord and left and right eyeballs; $D E Q_{2}$ brain - dose equivalent 2 Gy of the dose in $1 \mathrm{~cm}^{3}$ of brain tissue

was 3.8 Gy (range 3-4.2 Gy), and $\mathrm{D}_{90}$ median of a single fraction was $5.2 \mathrm{~Gy}$ (range 3.7-5.8). The total dose depended on critical organs tolerance and was $15-20 \mathrm{~Gy}$. $\mathrm{D}_{100}$ total dose median was 15.4 Gy (range 10-19.5 Gy), and $\mathrm{D}_{90}$ total dose median was 20.6 Gy (range 16.1-26 Gy). The above mentioned doses were converted to BED and $\mathrm{DEQ}_{2}$. Biologic effective dose median in isodose encompassing the whole irradiated volume $\left(\mathrm{D}_{100}\right)$ of all treatment fractions was 20.7 Gy (range 13.4-27.1 Gy) and $\mathrm{DEQ}_{2}$ was 17.2 Gy (range 11.1-22.6 Gy). Biologic effective dose median in isodose encompassing $90 \%$ of the irradiated volume $\left(D_{90}\right)$ was 30.4 Gy (range 24.7-39.5 Gy) and $\mathrm{DEQ}_{2}$ was $25.3 \mathrm{~Gy}$ (range 20.6-32.9 Gy).
Clinical target volume, which received $100 \%$ dose, as well as $150 \%$ and $200 \%$ dose was characterized in Table 2. Dose homogeneity index (DHI) was calculated for each fraction. Dose homogeneity index median was 0.31 (range 0.18-0.68) (Table 2). Depending on the location of irradiated area, doses received by various critical organs were reported (Tables 3, 4 and 5).

\section{Early toxicity}

Treatment toxicity was evaluated using Common Terminology Criteria for Adverse Events (CTCAE) v.4.0 [5], and the radiotherapy related morbidity was measured 
Table 4. Doses in critical organs: lens, otical nerves and optic chiasma in individual patients (only Patients 2 and 4)

\begin{tabular}{|c|c|c|c|c|c|c|c|c|c|c|c|c|c|c|c|}
\hline & $\begin{array}{c}\text { Lens I. } \\
\text { max. }\end{array}$ & $\begin{array}{c}\text { BED } \\
\text { lens I. }\end{array}$ & $\begin{array}{l}\mathrm{DEQ}_{2} \\
\text { lens I. }\end{array}$ & $\begin{array}{c}\text { Lens } r . \\
\text { max. }\end{array}$ & $\begin{array}{l}\text { BED } \\
\text { lens } r \text {. }\end{array}$ & $\begin{array}{l}\mathrm{DEQ}_{2} \\
\text { lens r. }\end{array}$ & $\begin{array}{c}\text { Optic } \\
\text { n. l. } \\
\text { max. }\end{array}$ & $\begin{array}{c}\text { BED } \\
\text { optic } \\
\text { n. I. } \\
\text { max. }\end{array}$ & $\begin{array}{c}\mathrm{DEQ}_{2} \\
\text { optic } \\
\text { n. I. }\end{array}$ & $\begin{array}{l}\text { Optic } \\
\text { n. r. } \\
\text { max. }\end{array}$ & $\begin{array}{l}\text { BED } \\
\text { optic } \\
\text { n. r. }\end{array}$ & $\begin{array}{c}\mathrm{DEQ}_{2} \\
\text { optic } \\
\text { n. r. }\end{array}$ & $\begin{array}{c}\text { Optic } \\
\text { chiasm } \\
\text { max. }\end{array}$ & $\begin{array}{c}\text { BED } \\
\text { optic } \\
\text { chiasm }\end{array}$ & $\begin{array}{c}\mathrm{DEQ}_{2} \\
\text { optic } \\
\text { chiasm }\end{array}$ \\
\hline \multicolumn{16}{|l|}{ Patient 2} \\
\hline Fr 1 & 0.2 & 0.2 & 0.1 & 0.2 & 0.2 & 0.1 & 0.2 & 0.2 & 0.1 & 0.2 & 0.2 & 0.1 & 0.2 & 0.2 & 0.1 \\
\hline Fr 2 & 0.2 & 0.2 & 0.1 & 0.2 & 0.2 & 0.1 & 0.2 & 0.2 & 0.1 & 0.2 & 0.2 & 0.1 & 0.2 & 0.2 & 0.1 \\
\hline $\mathrm{Fr} 3$ & 0.2 & 0.2 & 0.1 & 0.2 & 0.2 & 0.1 & 0.2 & 0.2 & 0.1 & 0.2 & 0.2 & 0.1 & 0.2 & 0.2 & 0.1 \\
\hline $\mathrm{Fr} 4$ & 0.2 & 0.2 & 0.1 & 0.2 & 0.2 & 0.1 & 0.2 & 0.2 & 0.1 & 0.2 & 0.2 & 0.1 & 0.2 & 0.2 & 0.1 \\
\hline $\operatorname{Fr} 5$ & 0.2 & 0.2 & 0.1 & 0.2 & 0.2 & 0.1 & 0.2 & 0.2 & 0.1 & 0.2 & 0.2 & 0.1 & 0.2 & 0.2 & 0.1 \\
\hline Amount & 1.0 & 1.1 & 0.6 & 1.0 & 1.1 & 0.6 & 1.0 & 1.1 & 0.6 & 1.0 & 1.1 & 0.6 & 1.0 & 1.1 & 0.6 \\
\hline \multicolumn{16}{|l|}{ Patient 4} \\
\hline Fr 1 & 0.3 & 0.3 & 0.2 & 1.1 & 1.5 & 0.9 & 0.5 & 0.6 & 0.3 & 1.8 & 2.9 & 1.7 & 0.8 & 1.0 & 0.6 \\
\hline Fr 2 & 0.2 & 0.2 & 0.1 & 1.0 & 1.3 & 0.8 & 0.5 & 0.6 & 0.3 & 1.6 & 2.5 & 1.5 & 0.9 & 1.2 & 0.7 \\
\hline Fr 3 & 0.4 & 0.5 & 0.3 & 1.5 & 2.3 & 1.3 & 0.7 & 0.9 & 0.5 & 2.4 & 4.3 & 2.6 & 1.3 & 1.9 & 1.1 \\
\hline Amount & 0.9 & 1.0 & 0.6 & 3.6 & 5.1 & 3.0 & 1.7 & 2.0 & 1.2 & 5.8 & 9.7 & 5.8 & 3.0 & 4.0 & 2.4 \\
\hline
\end{tabular}

Lens I. max., lens r. max., Optic n. I. max., Optic n. r. max., optic chiasm max. - maximum dose in left and right lens, left and right otical nerves and optic chiasma; $B E D$ lens l., BED lens r., BED optic n. l., BED optic n. r., BED optic chiasm. - biologic effective dose of maximum dose in maximum dose in left and right lens, left and right otical nerves and optic chiasma; $D E Q_{2}$ lens l., $D E Q_{2}$ lens r., $D E Q_{2}$ optic n. l., $D E Q_{2}$ optic n. r., $D E Q_{2}$ optic chiasm - dose equivalent 2 Gy of maximum dose in left and right lens, left and right otical nerves and optic chiasma

using Radiation Therapy Oncology Group (RTOG) scale [6]. Despite close vicinity of many important structures in the head and neck area, no mechanical injury of these organs was observed either in course of the insertion procedure or while the applicators were remaining in the treatment site between subsequent treatment sessions. None of the patients suffered from paralysis in result of mechanical damage of the nerves. Due to abundant vascularity of head and neck organs, there was a small degree of bleeding at the time of applicator removal, which was resolved spontaneously. No hemorrhagic foci were found on CT scans taken after the insertion and removal of applicators. No clinical features of internal hemorrhage were observed in these patients. In 3 patients (Patients $2,3,4)$, due to location of the irradiated area and acute radiotherapy induced morbidity of the skin, RTOG scale Grade 1 occurred. In one patient (Patient 2), a few days after completion of brachytherapy, an infection of the irradiated area requiring antibiotic therapy, CTCAE scale Grade 2 occurred. We focused only on acute reactions because of short follow-up.

\section{Treatment efficiency}

In the period of observation lasting for 3 to 7 months (median 3.5 months), partial regression (PR) was observed in 2 patients and stable disease in other 2 patients. In Patient 1, within 3 months of observation, clinically confirmed partial regression occurred. Because of the general condition of the patient, no imaging examination was performed in this case. The patient died due to lung metastases 4 months after treatment completion. In Patient 2, disease regression was being confirmed in CT ex- amination throughout the 7 months' observation period. In Patients 3 and 4, the CT examination revealed disease stabilization after treatment completion.

\section{Quality of life}

After the treatment, in 3 patients' partial relief of some symptoms was observed. In Patient number 4, trismus status improved and pain symptoms decreased. In Patient 2, despite intensified debilitation related to skin, an infection in the area of applicator insertion, dyspnea caused by tumor mass was reduced. In Patient number 1 , dysphagia related to tumor mass was reduced.

\section{Discussion}

The main factor limiting the application of HDR brachytherapy in the head and neck area is the tumor location. Due to the necessity of performing visually controlled application, brachytherapy in this area is only possible in case of lip cancer, oral cavity cancer, selected neoplasms of nasopharynx, nasal cavity and nasopharynx, as well as in case of repeated radiotherapy of nodular relapses in the head and neck area $[7,8,9,10,11,12,13,14]$.

Reports describing image guided brachytherapy predominantly concern liver, rectal, and lung cancers $[15,16,17,18,19,20,21]$. Studies concerning image guided brachytherapy in patients with head and neck cancer are singular. In analysis by Kolotas et al. [22], 49 patients with nodular relapse in the neck area were subjected to palliative interstitial brachytherapy. The insertion procedure was performed under CT guidance. The patients were irradiated twice a day with 3 Gy fractions up to 


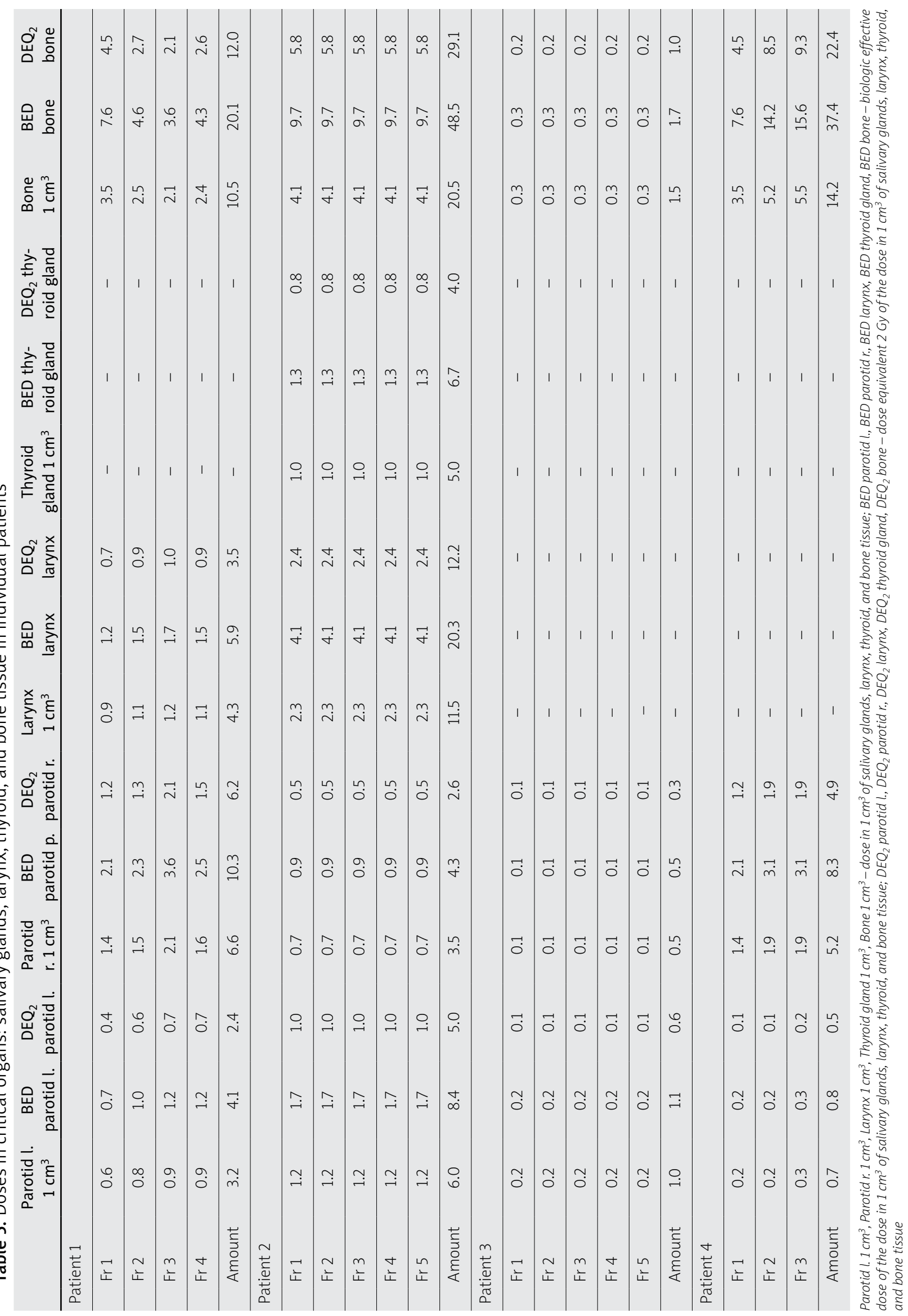


the total dose of 30-36 Gy. No significant complications were observed apart from the skin reaction. No patient experienced massive bleeding in course of the procedure. While, in a study by Jiang et al. [23], 25 patients with squamous cell carcinoma relapse in the area of head and neck were treated with brachytherapy using permanent implants. The procedure was performed under CT or USG guidance. The total dose specified in isodose encompassing 90\% CTV $\left(\mathrm{D}_{90}\right)$ was 90-160 Gy. No nerve paralysis or serious hemorrhage was observed. In a study by Kishan et al. [24] data were retrospectively analyzed from 18 patients with cancer, located in various areas including 2 in the head and neck area, who had undergone HDR brachytherapy performed under guidance of different imaging methods. Various dose fractioning schemes were used: $6 \mathrm{~Gy}$ in 6 fractions and $10 \mathrm{~Gy}$ in one fraction (as a boost after external beam radiation therapy). In one patient, the lesion was located directly close to the left internal carotid artery, and in other, one in soft tissues of the neck bordering the chest. Serious complications related to brachytherapy were not observed in any of the patients. Due to short observation time and small number of patients in the described study, the treatment results and late toxicity were not analyzed.

In our study, for four patients with relapsed neoplastic lesion located in a site preventing visually controlled brachytherapy, the application of CT image guided HDR brachytherapy facilitated the treatment in hardly accessible locations, too close to large nerves or blood vessels. Due to the use of different dose fractioning schemes than Kolotas et al. [22] and Kishan et al. [24], it is only possible to compare biological equivalent dose (BED) of the total dose. Biological equivalent dose of the total dose in Kolotas et al. was similar (32.5-39 Gy, $\alpha / \beta=10)$, and in Kishan et al. it was a little higher (48-56.7 Gy, $\alpha / \beta=10)$.

Similarly, to other studies, no complications occurred during application and no early toxicity was observed $[22,23,24]$. Moreover, positive effects were achieved in case of both treatment efficiency and quality of life. Due to the necessity of having appropriate technical facilities and difficulty of its application, brachytherapy is not commonly used. Thus, there are no studies based on large group of patients evaluating safety of the procedure and treatment results. There are also no studies comparing different application techniques as well as different types of applicators used in the head and neck region. The intention of image guided HDR brachytherapy is to provide local lesion control in sites, which, due to their extent or lack of technical facilities, do not qualify for using other radiotherapy techniques, especially stereotactic radiotherapy. There are no studies comparing image guided brachytherapy with modern techniques of stereotactic radiotherapy.

\section{Conclusions}

1. Image guided brachytherapy has the potential to be a valuable treatment method for patients with local and regional relapse of head and neck cancer located in sites preventing standard brachytherapy.

2. It is a safe method facilitating good therapeutic effect and improving the quality of patient's life.
3. It seems justified to conduct prospective studies to evaluate the efficiency and safety of CT image guided brachytherapy.

\section{Disclosure}

Authors report no conflict of interest.

\section{References}

1. Brockstein B, Haraf DJ, Rademaker AW et al. Patterns of failure, prognostic factors and survival in locoregionally advanced head and neck cancer treated with concomitant chemoradiotherapy: a 9-year, 337-patient, multi-institutional experience. Ann Oncol 2004; 15: 1179-1186.

2. Temam S, Pape E, Janot F et al. Salvage surgery after failure of very accelerated radiotherapy in advanced head and neck squamous cell carcinoma. Int J Radiat Oncol Biol Phys 2005; 62: 1078-1083.

3. Kovács G. Modern head and neck brachytherapy: from radium towards intensity modulated interventional brachytherapy. J Contemp Brachytherapy 2015; 6: 404-416.

4. Das R. ICRU 58 (Dose and Volume Specification for Reporting Interstitial Therapy), by International Commission on Radiation Units and Measurements. Med Phys 1998; 25: 1225.

5. https://evs.nci.nih.gov/ftp1/CTCAE/CTCAE_4.03_2010-0614_QuickReference_5x7.pdf [accessed 18 Jul 2016]

6. Cox JD, Stetz J, Pajak TF. Toxicity criteria of the Radiation Therapy Oncology Group (RTOG) and the European Organization for Research and Treatment of Cancer (EORTC). Int J Radiat Oncol Biol Phys 1995; 31: 1341-1346.

7. Serkies K, Ziemlevski A, Sawicki T et al. Pulsed dose rate brachytherapy of lip cancer. J Contemp Brachytherapy 2013; 5: 144-147.

8. Guinot JL, Arribas L, Tortajada MI et al. From low-dose-rate to high-dose-rate brachytherapy in lip carcinoma: Equivalent results but fewer complications. Brachytherapy 2013; 12 : 528-534.

9. Liu Z, Huang S, Zhang D. High dose rate versus low dose rate brachytherapy for oral cancer - a meta-analysis of clinical trials. PLoS One 2013; 8: e65423.

10. Yamazaki H, Yoshida K, Yoshioka Y et al. High dose rate brachytherapy for oral cancer. J Rad Res 2013; 54: 1-17.

11. Strnad V, Melzner W, Geiger M et al. Role of interstitial PDR brachytherapy in the treatment of oral and oropharyngeal cancer. A single-institute experience of 236 patients. Strahlenther Onkol 2005; 181: 762-767.

12. Nose T, Koizumi M, Nishiyama K. High-dose-rate interstitial brachytherapy for oropharyngeal carcinoma: results of 83 lesions in 82 patients. Int J Radiat Oncol Biol Phys 2004; 59: 983-991.

13. Rosenblatt E, Abdel-Wahab M, El-Gantiry Met al. Brachytherapy boost in locoregionally advanced nasopharyngeal carcinoma: a prospective randomized trial of the International Atomic Energy Agency. Radiat Oncol 2014; 9: 67-78.

14. Teudt IU, Kovàcs G, Ritter $M$ et al. Intensity modulated perioperative HDR brachytherapy for recurrent and/or advanced head and neck metastases. Eur Arch Otorhinolaryngol 2016; 273: 2707-2715.

15. Ricke J, Wust P, Stohlmann A et al. CT-guided interstitial brachytherapy of liver malignancies alone or in combination with thermal ablation: phase I-II results of a novel technique. Int J Radiat Oncol Biol Phys 2004; 58: 1496-1505.

16. Collettini F, Singh A, Schnapauff D et al. Computed-tomography-guided high-dose-rate brachytherapy (CT-HDRBT) ablation of metastases adjacent to the liver hilum. Eur J Radiol 2013; 82: e509-514. 
17. Collettini F, Lutter A, Schnapauff D et al. Unresectable colorectal liver metastases: percutaneous ablation using CT-guided high-dose-rate brachytherapy (CT-HDBRT). Rofo 2014; 186: 606-612.

18. Denecke T, Stelter L, Schnapauff D et al. CT-guided Interstitial Brachytherapy of Hepatocellular Carcinoma before Liver Transplantation: An Equivalent Alternative to Transarterial Chemoembolization? Eur Radiol 2015; 25: 2608-2616.

19. Sharma DN, Thulkar S, Sharma S et al. High-dose-rate interstitial brachytherapy for liver metastases: first study from India. J Contemp Brachytherapy 2013; 5: 70-75.

20. Bishop AJ, Gupta S, Cunningham MG et al. Interstitial Brachytherapy for the Treatment of Locally Recurrent Anorectal Cancer. Ann Surg Oncol 2015; 22: 596-602.

21. Tselis N, Ferentinos K, Kolotas C et al. Computed tomography-guided interstitial high-dose-rate brachytherapy in the local treatment of primary and secondary intrathoracic malignancies. J Thorac Oncol 2011; 6: 545-552.

22. Kolotas C, Tselis N, Sommerlad M et al. Reirradiation for recurrent neck metastases of head-and-neck tumors using CT-guided interstitial 192Ir HDR brachytherapy. Strahlenther Onkol 2007; 183: 69-75.

23. Jiang YL, Meng N, Wang JJ et al. Percutaneous computed tomography/ ultrasonography-guided permanent iodine-125 implantation as salvage therapy for recurrent squamous cell cancers of head and neck. Cancer Biol Ther 2010; 9: 959-966.

24. Kishan AU, Lee EW, McWilliams J et al. Image-guided highdose-rate brachytherapy: preliminary outcomes and toxicity of a joint interventional radiology and radiation oncology technique for achieving local control in challenging cases. J Contemp Brachytherapy 2015; 7: 327-335. 
